\title{
Pattern of outpatient utilisation and cost for patients under the Universal Coverage
}

\author{
Kanet Sumputtanon ${ }^{1 *}$, Nilawan Upakdee ${ }^{2}$, Pudtan Phanthunane ${ }^{3}$, Supasit Pannarunothai ${ }^{4}$ \\ From 7th Postgraduate Forum on Health Systems and Policies \\ Phitsanulok, Thailand. 24-25 June 2013
}

\section{Background}

Universal Coverage (UC) is a public health insurance scheme covered approximately 48.3 million of Thai population (74.3\% of total) in 2011. This study aimed to categorise pattern of outpatient utilisation and examine the relationship between an annual cost of outpatient service and pattern of utilisation.

\section{Materials and methods}

Outpatient data from the National Health Security Office in 2011 were analysed, 4 provinces were picked to represent the pattern of service utilisation. The selection criteria emphasised on 1) availability of various types of hospitals in the province (health promoting, community, general/ regional, university hospital; and others), and 2) the maximum utilisation rate of people in the province. Descriptive statistical analysis was employed to calculate annual utilisation. One-way analysis of variance was used to calculate the association between the annual costs per person and the pattern of service utilisation (whether rural or urban or both; and the type of hospital).

\section{Results}

Most common single users were at the health promoting hospitals (26.2\%-32.3\%), followed by community hospitals (17.6\%-22.6\%) and general/regional hospitals (2.8\%-13.9\%). For two-service-type users, the most common was the combination of health promoting hospitals and community hospitals (14.1\%-23.5\%), followed by health promoting and general/regional hospitals (2.3\%-7.4\%), and community hospitals and general /regional hospitals (1.5\%-3.8\%). For three-service-type users, most occurred at health promoting, community and general/regional hospitals (2.0\%-5.0\%). The other patterns were less than $1.0 \%$.

\footnotetext{
* Correspondence: kanet@hsri.or.th

${ }^{1}$ Health Systems Research Institute, Nonthaburi 11000, Thailand

Full list of author information is available at the end of the article
}

All four provinces had a similar pattern of urban $(42.8 \%$ $52.0 \%)$, urban and rural (24.4\%-29.8\%), and rural only (19.6\%-27.9\%). Costs per patient per year were significantly different between those using hospital combination and geographical area. Homogeneous subsets test suggested seven utilization patterns.

\section{Conclusions}

Different pattern of outpatient utilisation should be taken into account for policy formulation of capitation payment and allocation criteria.

\section{Authors' details \\ ${ }^{1}$ Health Systems Research Institute, Nonthaburi 11000, Thailand. ${ }^{2}$ Faculty of Pharmaceutical Sciences, Naresuan University, Phitsanulok 65000, Thailand. \\ ${ }^{3}$ Faculty of Business, Economics and Communications, Naresuan University, Phitsanulok 65000, Thailand. ${ }^{4}$ Faculty of Medicine, Naresuan University, Phitsanulok 65000, Thailand.}

Published: 29 January 2014

doi:10.1186/1471-2458-14-S1-P9

Cite this article as: Sumputtanon et al:: Pattern of outpatient utilisation and cost for patients under the Universal Coverage. BMC Public Health 2014 14(Suppl 1):P9.

Submit your next manuscript to BioMed Central and take full advantage of:

- Convenient online submission

- Thorough peer review

- No space constraints or color figure charges

- Immediate publication on acceptance

- Inclusion in PubMed, CAS, Scopus and Google Scholar

- Research which is freely available for redistribution

Submit your manuscript at www.biomedcentral.com/submit
C Biomed Central 